\title{
Loss of effectiveness of protective clothing after its use in pesticide sprays and its multiple washes
}

\section{Melina Espanhol-Soares, Manuela Teodoro de Oliveira \& Joaquim Gonçalves Machado-Neto}

To cite this article: Melina Espanhol-Soares, Manuela Teodoro de Oliveira \& Joaquim Gonçalves Machado-Neto (2017) Loss of effectiveness of protective clothing after its use in pesticide sprays and its multiple washes, Journal of Occupational and Environmental Hygiene, 14:2, 113-123, DOI: $\underline{10.1080 / 15459624.2016 .1225159}$

To link to this article: https://doi.org/10.1080/15459624.2016.1225159

Accepted author version posted online: 19

Aug 2016.

Published online: 21 Dec 2016.

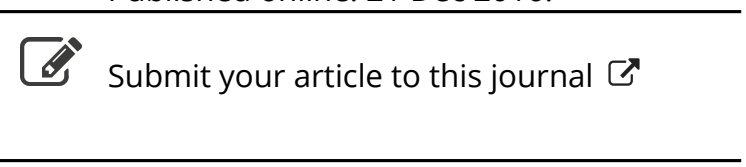

Џ Article views: 322

View Crossmark data ¿

Citing articles: 1 View citing articles $\square$ 


\title{
Loss of effectiveness of protective clothing after its use in pesticide sprays and its multiple washes
}

\author{
Melina Espanhol-Soares ${ }^{a}$, Manuela Teodoro de Oliveira ${ }^{b}$, and Joaquim Gonçalves Machado-Neto ${ }^{b}$ \\ a Institute of Science, Universidade Federal de Itajubá, Itajubá, Minas Gerais, Brazil; ${ }^{b}$ Department of Crop Protection, Universite Estadual Paulista, \\ Jaboticabal, São Paulo, Brazil
}

\begin{abstract}
Protective clothing is used as a barrier against pesticides when working with agricultural sprays. The aim of this study was to evaluate the pesticide penetration, retention, and repellence of the material and seams of a whole-body protective garment used by applicators of pesticides. The efficiency of the material and seams of the whole-body garment were determined for its classification as proposed by ISO 27065 (ISO, 2011). The evaluation method used was the pipette test of ISO 22608. The efficiency of the material and seams of the garment (100\% cotton) were tested by contamination with formulations of Roundup Original ${ }^{\circledR}$ SL; Nufos $\mathrm{EC}^{\circledR}$ and Supera SC ${ }^{\circledR}$. The presence of the seams in the protective clothing reduced its efficiency in the control of dermal exposure, except when protecting against the Supera $\mathrm{SC}^{\circledast}$ formulation. The number of washes and uses affected the efficiency of the material and seams of the garment. The type of formulation interfered significantly in the penetration of pesticides into the material and seams. Thus, the laboratory efficiency assessment of protective clothing is necessary to determine what types of formulations and use conditions are appropriate for workers.
\end{abstract}

\section{KEYWORDS}

Efficiency testing; penetration of pesticide; pipette test; protective material

\section{Introduction}

Protective clothing acts as a protective layer between the worker and pesticide contamination. ${ }^{[1]}$ Generally in hot climate countries the pesticide applicators wear porous protective clothing, such as cotton, that are comfortable and breathable. Variation in the efficiency of protective clothing used by agricultural workers is often related to the type of work performed by pesticide applicators, given that direct and continuous contact of clothing with plants can reduce the control of dermal exposure by PPE (personal protective equipment). ${ }^{[2]}$ Different formulation types (emulsifiable concentrated, soluble concentrated, suspension concentrated, and others) influence the penetration of protective clothing fabric when handled differently. ${ }^{[3]}$ The inefficiency of protective clothing is due to misapplication or poorly made clothing favouring the penetration of pesticides into the garments through openings, seams, and zippers. ${ }^{[2]}$

The quantification of repellence, pesticide retention, and penetration testing are the characteristics used to determine the efficiency of porous materials in protective clothing against pesticides. ${ }^{[4]}$ Chemical penetration is passage that crosses through openings, pores in the material, seams, holes, or other imperfections occurring in the set. ${ }^{[5]}$ Factors that can contribute to the penetration of liquids through such material include surface tension, viscosity, pore geometry, and thickness of the fabric, ${ }^{[6]}$ and wear by abrasion of the mechanical washing process. ${ }^{[7]}$

The registration of pesticide products involves the assessment of operator exposure and risk; factors that determine the need to use personal protective equipment. ${ }^{[8]}$ The efficiency of protective clothing material used by rural workers against penetration can be assessed in laboratory tests by measuring repellence, retention and penetration of pesticides, as well as fabric seam porosity, as described in ISO 27065 standard. ${ }^{[8]}$ The protocol is ISO 22608 for material resistance to pesticides, which uses a pipette containing the pesticide that will be in contact with the material, without the use of mechanical pressure or hydrostatic force in the application of the pesticide. ${ }^{[9]}$

To choose the best type of protective clothing, it is necessary to know the level of protection required for each pesticide formulation that is handled by the applicators,

CONTACT Melina Espanhol-Soares melespanhol@yahoo.com.br Institute of Science, Universidade Federal de Itajubá, Avenue BPS, 1303, Itajubá, Minas Gerais, 37500-903, Brazil.

Color versions of one or more of the figures in the article can be found online at www.tandfonline.com/uoeh.

() 2017 JOEH, LLC 
as well as to determine its application conditions. Thus, the aim of this work is to evaluate the penetration and retention of pesticides and the repellence of the material and seams of whole-body protective garments used by applicators of pesticides; determining the efficiency of the material and seams for the classification proposed by ISO 27065 in relation to the type of formulation and its dilution tested, the chemical-physical characteristics of the active ingredient, the mode of use of the garment, and the number of washes.

\section{Material and methods}

\section{Contamination of pesticides}

This research evaluated the efficiency of material and seams of protective water-repellent clothing, either used by rural workers in the field or unused, both washed. The efficiency was evaluated in accordance with ISO 22608.

The pesticides used in the ISO 22608 test were diluted and undiluted: glyphosate-Roundup Original SL - soluble concentrated; chlorpyrifos - Nufos EC - emulsifiable concentrated; and copper hydroxide - Supera $\mathrm{SC}^{\oplus}$ - suspension concentrated. The respective formulations were diluted to a final concentration of $5 \%$ of the active ingredient, according to ISO 22608. The physicalchemical parameters of the formulations and their respective dilutions are shown in Table 1.

Surface tension was measured according to ASTM test method D 3825-09 (ASTM, 2009) with a tensiometer model QC 6000 (Sensadyne Div. Instr.) at $25^{\circ} \mathrm{C}$. ${ }^{[10]}$ The kinematic viscosity of the pesticide mixtures were measured according to ASTM D 2196-10, with viscometer model DV- I Prime (Brookfield), at $25^{\circ} \mathrm{C}$. For this method a speed of $50 \mathrm{rpm}$ was used and the spin was set at n.61. ${ }^{[11]}$ The conductivity was measured with a conductivity metre model Q - 795A2 (Quimis), calibration being performed with standardized potassium chloride.

\section{Protective clothing}

Description: The personal protective clothing evaluated is composed of $100 \%$ cotton, weight: $143.4 \mathrm{~g} \mathrm{~m}^{-2}$; structure: plain woven; fabric count (yarns/cm): 23 (warp) and 21 (weft). The fabric was coated with fluorocarbon finish to provide water repellence. The seams of garments have: stitch density: 6 stitches $/ \mathrm{cm}$; sewing thread: cotton; stitch type: single chainstitch. The garment included 3 pieces: pants, a long-sleeved shirt, and a cap-type hood with fabric to protect the neck and shoulders. The material thickness of garments after washing was measured according to ASTM D 177-96 with the device Mainard Brand, Model M-73210, with centesimal precision $(0.01 \mathrm{~mm})$ and $120 \mathrm{~mm}$ deep. The spring pressure of the device was $10 \mathrm{kPa}^{[12]}$

\section{Conditions of use and washing}

The personal protective was used and washed or just washed. Under field conditions in citrus crops, with tractor activity being considered less aggressive than the activity of directly applying glyphosate spray to adult cultures. The use in sugar cane crop was considered more aggressive, due the contact with the plants. After each use in the field the garments were washed. The protective clothing that saw no use was only washed in the laboratory. For each use situation (field and laboratory) were used 4 protective garments at the various intervals of $0,5,10,20$, and 30 uses (field) and washes, A total number of 60 test garments. The garment was ironed after drying according to the manufacturer's recommendations.

\section{Use in cane sugar}

The personal protective garments were washed after of each use under field conditions and, this procedure was performed 30 times. They were used by field workers without the addition of glyphosate in applications for weed control. Not adding of the glyphosate in the herbicide spray was chosen to avoid interference in the evaluation of efficiency. The workers who applied herbicide walked between plant rows. The plants had $1.4 \mathrm{~m}$ between them and were 1.5-2.5 $\mathrm{m}$ tall. A knapsack sprayer was used to apply spray for weed control. Workers were equipped with a flat fan nozzle that sprayed at an average pressure of $35 \mathrm{psi}$. The application lance was placed on

Table 1. Mean and standard deviations of Physical-chemical parameters of diluted and undiluted formulation of Roundup Original SL, Nufos EC, and Supera SC.

\begin{tabular}{|c|c|c|c|c|}
\hline \multirow[b]{2}{*}{ Formulations } & \multicolumn{4}{|c|}{ Physical-chemical parameters } \\
\hline & $\mathrm{pH}$ & Tension of the liquid spray (dyn $\mathrm{cm}^{-1}$ ) & Viscosity (cP) & Condutivity $(\mu \mathrm{s} / \mathrm{cm})$ \\
\hline Nufos EC 5\% a.i. & $3.4 \pm 0.1$ & $30.4 \pm 0.3$ & $2.3 \pm 0.500$ & $99.1 \pm 2.6$ \\
\hline Nufos EC & $2.5 \pm 0.1$ & $30.3 \pm 0.5$ & $8.1 \pm 0.4$ & $0.0 \pm 0.0$ \\
\hline Roundup Original SL 5\% a.i. & $4.4 \pm 0.1$ & $44.8 \pm 0.7$ & $1.4 \pm 0.6$ & $745.0 \pm 3.1$ \\
\hline Roundup Original SL & $4.7 \pm 0.2$ & $39.0 \pm 0.3$ & $39.6 \pm 2.6$ & $537.0 \pm 2.5$ \\
\hline Supera SC 5\% a.i. & $8.7 \pm 0.3$ & $32.8 \pm 0.2$ & $1.8 \pm 0.2$ & $217.0 \pm 1.1$ \\
\hline Supera SC & $8.2 \pm 0.2$ & $43.4 \pm 0.6$ & $586.0 \pm 5.3$ & $1335.0 \pm 14$ \\
\hline
\end{tabular}


the right side of the worker and the nozzle kept at $0.5 \mathrm{~m}$ above the highest leaves of the weeds. After each workday ( $7 \mathrm{hr}$ ) of exposure, the garments were washed with neutral liquid coconut soap in an SLE-50M Washer, from SITEC, which belongs to the sugar cane plantation. The washing procedure was the original gentle program of the washer itself. Then, the sample clothing was dried in the centrifugal extractor SP-30M. The garments were ironed at $110^{\circ} \mathrm{C}$ of according to the manufacturer's recommendations.

\section{Use in citrus}

The personal protective clothing was used for workers in tractor activity (air blast sprayer) in the application of citrus plants. Pesticides were not added due to its noninterference in the evaluation of protective clothing efficiency.

The average flow of the three nozzle spray was 1.44 $\mathrm{L} / \mathrm{min}$ with a pressure of $100 \mathrm{PSI}$. The average time of application was $30 \mathrm{~min}$ for each repetition, and 17.5 L/plant, with $1000 \mathrm{~L}$ of spray liquid. After each workday ( $7 \mathrm{hr}$ ) of exposure, the garments were washed with neutral liquid coconut soap in a Turbo- $8 \mathrm{~kg}$ Washer, from Electrolux. The washing procedure was the original gentlesynthetic program of the washer itself, done in 3 steps: stirring for $10 \mathrm{~min}$, rinse for $18 \mathrm{~min}$, and centrifuged for $18 \mathrm{~min}$. The garments were ironed at $110^{\circ} \mathrm{C}$ after drying, according to the manufacturer's recommendations.

\section{Washing in laboratory}

The garment not used in the field was just washed in laboratory according to ISO 6330 in the FOM 71 CLS Washer from Electrolux. Each washing cycle was carried out with $2 \mathrm{~kg}$ of clothes, 4 sets of protective garment, $50 \mathrm{~g}$ of soap AATCC 1993 as recommended in ISO 6330, Annex A. The standard washing procedure lasted $30 \mathrm{~min} .{ }^{[13]}$ The garments were ironed at $110^{\circ} \mathrm{C}$ after drying, according to the manufacturer's recommendations.

\section{Test assembly}

$8 \times 8 \mathrm{~cm}$ samples of material were cut from protective clothing used in the fields (citrus and sugar cane) and washed in the laboratory only. The samples were cut from the head + neck, front torso, back torso, arms, front leg, and back leg of the sets of personal protective clothing (Figure 1) and washed. The seams of the hood, arm, chestsides and leg-sides were also evaluated. The pieces were cut from the protective garment with $0,5,10,20$, and 30 uses (field) and washes. These samples were collected six times for each part of the body to measure percentage penetration, retention and repellency according to ISO 22608 (gravimetric method).

The test assembly consisted of an $8 \times 8 \mathrm{~cm}$ test fabric (top layer) and an $8 \times 8 \mathrm{~cm}$ absorbent paper backed

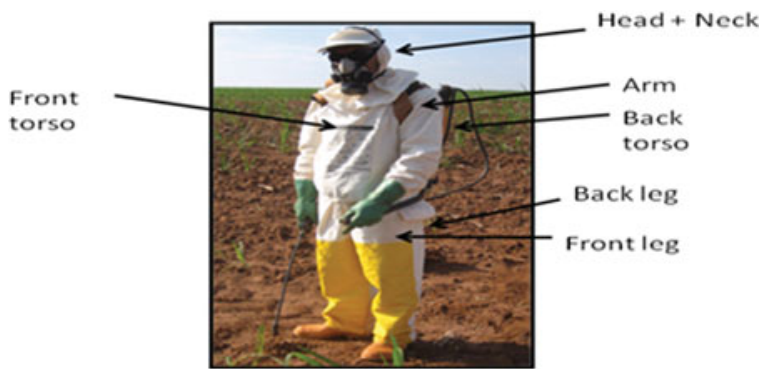

Figure 1. Protective clothing used to glyphosate herbicide in applications for weed control and respective regions evaluated.

with polyethylene film (Whatman Benchkote Plus with polyethylene backing, Whatman $3 \mathrm{~mm}$ CR, Whatman PLC, Whatman House, Kent, U.K.) held together between two Plexiglas plastic plates, a base plate and a cover plate. The cover plate had a $6 \times 6 \mathrm{~cm}$ opening (Figure 2 ).

Before the test were weighted the fabric specimen and the two absorbent papers. A micropipette with a disposable tip was used to apply $0.2 \mathrm{~mL}$ of the pesticide as one droplet to the center of the fabric specimen (material or seam). For repellent fabrics, a second absorbent paper with polyethylene backing was placed between the fabric and the top frame, following $10 \mathrm{~min}$ of pesticide contact. After this time, the absorvent layer, used to measure repellency, was placed between the fabric specimen for $2 \mathrm{~min}$. The three layers (absorbent paper and fabric) were separated and re-weighed. The fabric test specimens and absorbent paper were conditioned and tested at $\left(20 \pm 5^{\circ} \mathrm{C}\right)$ and $60 \pm 10 \%$ relative humidity for $24 \mathrm{hr}$ before testing. There were six replicates for each different part of the body evaluated, a total number 48 samples for each interval of uses or/and washes $(0,5,10,20$, and 30).

\section{Analyses of pippet method}

The percentage of repellency, retention, and penetration of formulation (diluted and undiluted) of pesticides were calculated according to the procedures established in ISO 22608 standards. ${ }^{[10]}$ For the percentages were calculated

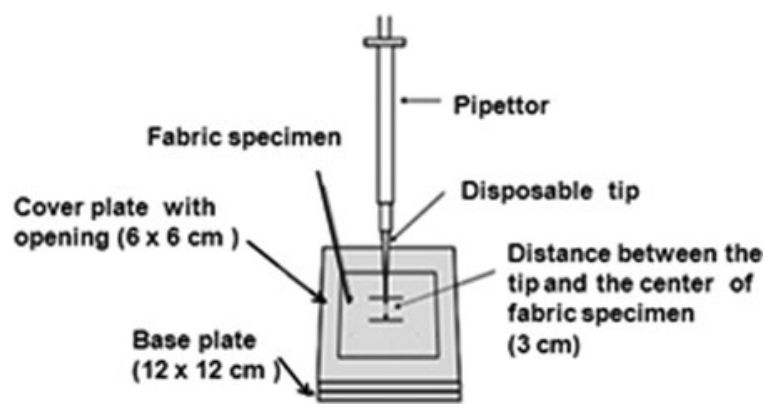

Figure 2. Scheme of test assembly. 


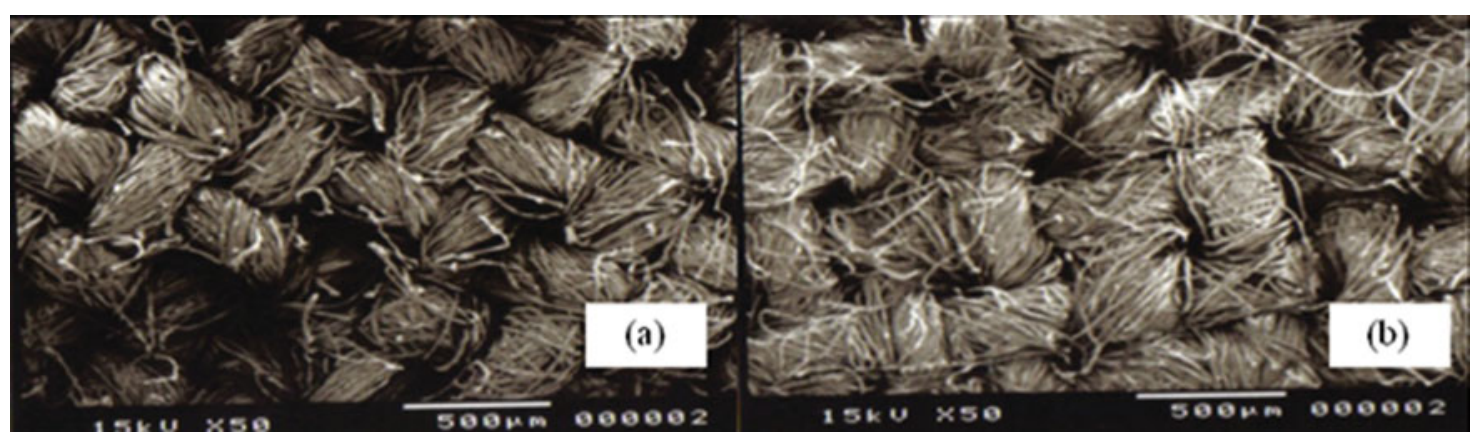

Figure 3. SEM micrographs of materials of protective clothing: (a) material used in the cultivation of sugarcane and washed 30 times and (b) material without use or washing.

using the following formulas:

$$
\begin{aligned}
& \text { Percent repellency }(P R)=M_{R} \times 1 O O / M_{t}, \\
& \text { Percent Retention }(P L R)=M_{P r} \times 1 O O / M_{t}, \\
& \text { Percent penetration }(P P)=M_{P} \times 1 O O / M_{t},
\end{aligned}
$$

where

$\mathrm{M}_{\mathrm{r}}=\operatorname{mass}(\mathrm{g})$ of liquid pesticide retained in absorbent paper used to remove excess after 10 minutes;

$\mathrm{M}_{\mathrm{Pr}}=$ mass $(\mathrm{g})$ of liquid pesticide retained from the protective clothing material specimen,

$\mathrm{M}_{\mathrm{p}}=$ mass (g)of liquid pesticide in the collector layer, $\mathrm{M}_{\mathrm{t}}=$ total mass(mg) of liquid pesticide.

\section{Morphology of fabric}

The fabric samples of protective clothing were cut into pieces $1 \times 1 \mathrm{~cm}$ and placed on a metal ribbon on a specimen holder and identified of the according with use situation and washes. The fabric samples were metallized with gold by a nebulizer S desk model II, Denton Vacuum brand, and after this procedure the samples were photographed with a scanning electron microscope (SEM), JEOL JSM 5410 scanning microscope model. The captured images were enlarged by 50 times, operating at a voltage of $15 \mathrm{KV}$.

\section{Classification of materials and seams}

The efficiency of the material and seams of tested protective clothing, were classified by ISO 27065 after the ISO 22608 test. ISO 27065 classifies useful life of garment material and seams based on the penetration of diluted or undiluted pesticides formulation of $\leq 5 \%$; above this value garments were considered to have failed. ${ }^{[8]}$

\section{Statistical analysis}

The calculated penetration values were analyzed statistically using a completely randomized design using $\mathrm{F}$ test for variance, and Scott and Knott analysis for the comparison of averages. ${ }^{[14]}$ The Sisvar program was used. ${ }^{[15]}$

\section{Results and discussion}

\section{Effect of use of material on morphology}

The morphology of the fabric fibres of the clothing used in the field or only washed in the laboratory is shown in Figure 3. The fabric was used and washed 30 times (Figure 3a), and it showed that more fabric yarns were loosened when the fabric was used in the field than when it was washed only (Figure 3b).

The thickness of the fabric washed in the laboratory increased by $37.5 \%$ with an initial thickness of $0.4 \mathrm{~mm}$ and final thickness of $0.55 \mathrm{~mm}$ after 30 washes; this effect may be due to the yarns becoming looser. The thickness of the fabric used in citrus increased $43.7 \%$ after 30 washes to $0.57 \mathrm{~mm}$. For the fabric used in sugarcane and washed 30 times, the increase was $52.5 \%$ with $0.61 \mathrm{~mm}$.

Csiszar observed in electron microscopy the effectiveness of the starch and carboxymethylation finishes on decontamination of the methyl parathion after one wash, and verified little residue on the fabric surfaces. ${ }^{[16]}$ Other authors such as Faulde et al. observed by scanning electron microscopy that after 10 washes the fabric of workers' uniforms had ruptures of the ligaments between the fibres of the fabric. ${ }^{[17]}$ Various types of fabric with different constituents such as polyester, cotton, and polyamide were washed several times according to the ISO 6330 standard, which modified the main characteristics such as weight, thickness and weft direction of the fabric fibers. ${ }^{[7]}$

\section{Penetration of the formulations}

\section{Material of garment}

Use and wash. The average penetration of pesticide into the water-repellent material used in the field, then 
Table 2. Percentages of penetrations values of formulations de Roundup Original SL, Nufos EC, and Supera SC, through material of garment.

\begin{tabular}{|c|c|c|c|c|c|c|c|c|}
\hline \multirow[b]{3}{*}{ Uses and washes } & \multirow[b]{3}{*}{ Conditions } & \multicolumn{6}{|c|}{ Formulations } & \multirow[b]{3}{*}{$P$ value } \\
\hline & & \multicolumn{2}{|c|}{ Roundup Original SL } & \multicolumn{2}{|c|}{ Nufos EC } & \multicolumn{2}{|c|}{ Supera SC } & \\
\hline & & Diluted & Undiluted & Diluted & Undiluted & Diluted & Undiluted & \\
\hline \multirow[t]{4}{*}{0} & Laboratory & $2.8 \mathrm{Aa}^{1}$ & $1.1 \mathrm{Aa}$ & $4.2 \mathrm{~A} \mathrm{a}$ & $0.9 \mathrm{Aa}$ & $2.3 \mathrm{Aa}$ & $1.5 \mathrm{Aa}$ & 0.78 \\
\hline & Citrus & $1.7 \mathrm{~A} \mathrm{a}$ & $1.4 \mathrm{~A} \mathrm{a}$ & $3.3 \mathrm{~A} \mathrm{a}$ & $1.0 \mathrm{Aa}$ & $3.6 \mathrm{~A} \mathrm{a}$ & $2.6 \mathrm{Aa}$ & 0.87 \\
\hline & Sugarcane & $3.0 \mathrm{Aa}$ & $1.6 \mathrm{Aa}$ & $4.6 \mathrm{~A} \mathrm{a}$ & $0.6 \mathrm{Aa}$ & $3.0 \mathrm{~A} \mathrm{a}$ & $1.9 \mathrm{~A} \mathrm{a}$ & 0.35 \\
\hline & $P$ value & 0.78 & 0.45 & 0.89 & 0.67 & 0.98 & 1.23 & \\
\hline \multirow[t]{4}{*}{5} & Laboratory & $1.9 \mathrm{~B} \mathrm{a}$ & $1.3 \mathrm{~B} \mathrm{a}$ & $4.5 \mathrm{Ab}$ & $1.6 \mathrm{~B} \mathrm{a}$ & $2.5 \mathrm{BC}$ & $2.6 \mathrm{~B} \mathrm{a}$ & 0.01 \\
\hline & Citrus & $2.3 \mathrm{~B} \mathrm{a}$ & $1.5 \mathrm{~B} \mathrm{a}$ & $5.5 \mathrm{~B} \mathrm{~b}$ & $1.5 \mathrm{~B} \mathrm{a}$ & 83.7 A a & $2.4 \mathrm{~B} \mathrm{a}$ & 0.01 \\
\hline & Sugarcane & $3.0 \mathrm{~B} \mathrm{a}$ & $2.2 \mathrm{Ca}$ & 11.1 B a & $3.9 \mathrm{Ca}$ & 74.6 A b & $1.3 \mathrm{Ca}$ & 0.01 \\
\hline & $P$ value & 0.83 & 0.91 & 0.00 & 0.67 & 0.03 & 0.45 & \\
\hline \multirow[t]{4}{*}{10} & Laboratory & $3.2 \mathrm{~B} \mathrm{a}$ & $1.1 \mathrm{~B} \mathrm{a}$ & $8.0 \mathrm{Ab}$ & $1,8 \mathrm{BC}$ & $6.1 \mathrm{Ab}$ & $3.9 \mathrm{~B} \mathrm{a}$ & 0.00 \\
\hline & Citrus & $4.0 \mathrm{~B} \mathrm{a}$ & $1.9 \mathrm{Da}$ & $6.7 \mathrm{Cb}$ & 21.9 B b & $80.8 \mathrm{~A} a$ & $1.9 \mathrm{Da}$ & 0.01 \\
\hline & Sugarcane & 4.2 D a & $2.2 \mathrm{D} \mathrm{a}$ & $72.4 \mathrm{~B} \mathrm{a}$ & $63.7 \mathrm{Ca}$ & 77.7 A a & $2.3 \mathrm{Da}$ & 0.01 \\
\hline & $P$ value & 0.67 & $0.45^{\mathrm{NS}}$ & 0.02 & 0.03 & 0.04 & 0.67 & \\
\hline \multirow[t]{4}{*}{20} & Laboratory & $3.7 \mathrm{Cb}$ & $1.3 \mathrm{Ca}$ & $11.1 \mathrm{~A} C$ & $1,9 \mathrm{Cc}$ & 8.2 B b & $2.6 \mathrm{Ca}$ & 0.01 \\
\hline & Citrus & $4.2 \mathrm{~B} \mathrm{~b}$ & $1.3 \mathrm{~B} \mathrm{a}$ & 64.1 A b & $78.4 \mathrm{~A} \mathrm{~b}$ & 74.8 A a & $2.1 \mathrm{~B} \mathrm{a}$ & 0.01 \\
\hline & Sugarcane & 8.1 Da & $3.0 \mathrm{E} \mathrm{a}$ & $74.3 \mathrm{Ca}$ & 84.0 A a & $77.9 \mathrm{~B}$ a & $2.5 \mathrm{E} \mathrm{a}$ & 0.02 \\
\hline & $P$ value & 0.00 & 0.65 & 0.04 & 0.03 & 0.02 & 0.76 & \\
\hline \multirow[t]{4}{*}{30} & Laboratory & $2.9 \mathrm{Cb}$ & $0.8 \mathrm{Ca}$ & $11.0 \mathrm{~B} \mathrm{C}$ & $2.4 \mathrm{CC}$ & 13.8 A b & $2.8 \mathrm{Ca}$ & 0.02 \\
\hline & Citrus & $4.5 \mathrm{Cb}$ & $1.4 \mathrm{Ca}$ & $69.6 \mathrm{~B} \mathrm{~b}$ & 81.5 A b & $69.0 \mathrm{~B} \mathrm{~b}$ & $2.9 \mathrm{Ca}$ & 0.01 \\
\hline & Sugarcane & $70.5 \mathrm{~B} \mathrm{a}$ & $3.0 \mathrm{Ca}$ & $76.3 \mathrm{~B}$ a & 88.2 A a & $78.8 \mathrm{~B}$ a & $2,83 \mathrm{Ca}$ & 0.010 \\
\hline & $P$ value & 0.00 & 0.09 & 0.00 & 0.00 & 0.00 & 0.14 & \\
\hline
\end{tabular}

Note. ${ }^{1}$ Averages followed by same letter do not differ by Scott-Knott at $5 \%$ probability, lowercase letter, compared with the corresponding column for each condition (uses and washes), and capital letter, compared in the row corresponding type of pesticides formulations (diluted or undiluted). Bold percentages penetrations above $5 \%$ - failed by ISO 27065.

washed was higher than that of the material only washed in the laboratory, mainly to contamination with Nufos EC and diluted Supera SC (Table 2). The use interfered in the fabric's structure. The structure of fabric with waterrepellent treatment interferes in the absorption and retention of agrochemicals by the material. ${ }^{[1]}$ Consequently, the effects of use and washing may have removed part of the Teflon (the water-repellent finish).

The wear of the material from the number of uses and washings was positively correlated with increasing percentage of penetration (Table 2). The explanation is that washing alters the surface characteristics of water repellent material, as well as the structure and stability of the fiber, resulting in decreased protection. ${ }^{[18]}$ Sontara fabrics with water-repellent treatment, washed with mechanical stirring 10 times, showed a significant increase of $39 \%$ in the penetration of water after five washes, ${ }^{[19]}$ highlighting the loss of protection by waterproofed fabric was caused by mechanical washing procedures.

Another factor that decreases the water repellence of material is a wash process consisting of soap with lipases; after only a single washing, the amount of lipids is reduced in cotton fabrics with water-repellent treatment. ${ }^{[20]}$ The percentage penetration for material without use or wash was below $5 \%$ to formulations tested; similar results were reported by Shaw et al. and showed the percentage of mpenetration below $3 \%$ by the pipette test for material $\left(100 \%\right.$ cotton $\left.-277 \mathrm{~g} \mathrm{~m}^{-2}\right)$ with water-repellent finish without use or wash contaminated with diluted pesticide formulations of $5 \%$ a.i. atrazine (suspension concentrateds and water dispersible granules) and pendimethalin (emulsifiable concentrated). ${ }^{[3]}$

The abrasion of material used in sugar cane and citrus fields facilitated greater penetration of the diluted of Supera SC (above of 69\%) and of Nufos EC (above 64.1\% and $63 \%$ - diluted and concentrated) than did the material washed in the laboratory (up to $13.8 \%$ ). The highest penetration (70.5\%), by the diluted of Roundup Original SL into garment material used in the sugar cane crop, only occurred after 30 times, and it can be correlated to aggressive wear together with friction due to walking across the plant leaves.

Type offormulation. After five uses and/or washing, the diluted pesticides penetrated into the fabric more than the undiluted formulations. This is due to the lower values of tension and viscosity of the liquid formulations studied, which facilitated the pesticides' penetration into the material. ${ }^{[21]}$ In this situation of five uses (field) and washing, the penetration of 83.7 and $74.6 \%$ (use in citrus or sugar cane) of the Supera SC diluted was greater than that of Nufos EC and Roundup Original SL ${ }^{\oplus}$. The chlorpyrifos a.i of the Nufos formulation has low water solubility, as does the copper hydroxide of the Supera SC formulation, but the penetration of their diluted into the material were higher than that of Roundup Original, which has high solubility for glyphosate; this occurs due to the presence of 
surfactants and other inert agents that make the formulation water soluble.

The higher penetration of the diluted Supera SC into the material after five uses and washing cannot be attributed to surface tension or viscosity because its values are close to those of the other pesticides studied; a parameter that this increase of penetration could be attributed the lipophilicity. The influence of non-polar substances interferes in the mass transfer at surfaces such as skin and polymeric materials, as noted in the study of Hubal et al., is such that the penetration of a lipophilic tracer is greater than that of a hydrophilic tracer. ${ }^{[22]}$ Using the ISO 22608, Shaw and Abbi reported that the type of formulation was significant for the penetration of cotton and cottonblended fabrics with synthetic fibers without washing, but in this work the emulsifiable concentrated formulation showed greater penetration than the other types of formulations tested, such as water dispersible granules and suspension concentrateds. ${ }^{[4]}$

These data can be related to the factor of lipophilicity, where the (octanol/water partition coefficient) Kow of Nufos EC is 4.7 and that of Roundup Original SL is 7.94 $10^{-5}$, i.e., Nufos EC is almost 60,000 times more lipophilic than Roundup Original SL. ${ }^{[24]}$ The copper hydroxide (Supera SC) is in a suspension concentrated formulation, which provides solid particles suspended in aqueous phase due to an anionic/nonionic dispersant-wetting agent with surfactant and adjuvant viscosity. ${ }^{[23]}$

Classification. The material was classified in accordance with the ISO 27065 in the zero use or washing, because the penetration of diluted and undiluted formulations studied did not influence in the penetration of new fabric as values were less than $5 \%$. The penetration values were slightly higher for the diluted than for the pure formulations, but not significantly. After five uses and washings in the field, the clothing samples failed according to ISO 27065, as penetration of the Nufos EC and Supera SC diluted were higher than $5 \%$. This failure also occurred for material after 10 uses and washings tested with the Nufos EC. After 20 uses and washes, the material used in sugar cane was disqualified by the ISO test for the Roundup Original SL diluted. Under these conditions it is not recommended to use this material for protection against these pesticides.

The ISO 27065 standard: required that all material and seams of protective clothing be tested with a Prowl 3.3 pesticide-an emulsifiable concentrated or a replacement formulation more used and easily available. In Brazil, protective clothing for rural workers has been evaluated according to ISO 22608 with diluted Roundup 5\% and classified by ISO 27065. ${ }^{[8]}$ The results of this research showed that the penetration of diluted Supera SC ${ }^{\circledast}$ (suspension concentrated) into the garment after five field uses and washes was higher than $5 \%$ and greater than that of the two diluted formulations studied, i.e., there is a need to evaluate various formulations to obtain a protective clothing certification before being marketed. However, the material tested with Roundup Original SL and Supera SC can be mainly used in the preparation of pulverization liquid, which uses undiluted formulations.

This research revealed that use and washing effects interfered in classification by ISO 27065 , indicating that protective clothing certifications should consider the use and washing of clothing and not only the effect of washing.

\section{Seams of garments}

Use and washing. The contamination of seams reached penetration values between 40 and 50\% after five uses and washes. This interference also occurred for the undiluted formulation of Nufos EC in the same situation of use, with varying from 16.6-24.3\% (Table 3). Aprea et al. reported higher penetration of pesticides occurring in the presence of seams in their overall evaluation of Tyvek material. ${ }^{[2]}$ Use of the garment in the field was not significant for the penetration of the undiluted formulation of Supera SC or Roundup Original SL through seams within each wash cycle analysed, with values below $5 \%$ penetration. This is due to the high viscosity of the Supera SC, which prevents passage through the pores of the seams.

Penetration of diluted formulations of Nufos EC and Supera SC into the seams of the garment reached values as high as $61.4 \%$ and $53.2 \%$ during the use and washing cycles, and all penetration values exceeded $5 \%$. Increasing numbers of uses and washings increased the average penetration percentage for all conditions of use and for every pesticide studied. Increasing numbers of uses and washes increased the average percentage of penetration for all conditions of use and for each contaminating pesticide studied.

Type of formulation. The penetration values for the diluted formulations of Nufos EC and Supera SC were above $5 \%$ before any use or washing. The low values of viscosity (2.3 and $1.8 \mathrm{cP}$ ) and surface tension (30.4 and $32.8 \mathrm{dyn} \mathrm{cm}^{-1}$ ), which were similar for the diluted formulations, may have influenced penetration through the needle holes of the seams. Penetration of the undiluted Supera SC and Roundup Original SL formulations through the seams was below $5 \%$ for up to 30 uses and washings. This could be explained by the high viscosities, which hindered transport through the pore spaces of the seams. The penetration of the undiluted formulations of Supera SC and Roundup Original SL through seams was less than $5 \%$ until 30 uses and washes, and these values can 
Table 3. Percentages of penetrations values of formulations of Roundup Original SL, Nufos EC, and Supera SC, in seam of garment.

\begin{tabular}{|c|c|c|c|c|c|c|c|c|}
\hline \multirow[b]{3}{*}{ Uses and Washes } & \multirow[b]{3}{*}{ Conditions } & \multicolumn{6}{|c|}{ Formulations } & \multirow[b]{3}{*}{$P$ value } \\
\hline & & \multicolumn{2}{|c|}{ Roundup Original SL ${ }^{\oplus}$} & \multicolumn{2}{|c|}{ Nufos EC } & \multicolumn{2}{|c|}{ Supera SC } & \\
\hline & & Diluted & Undiluted & Diluted & Undiluted & Diluted & Undiluted & \\
\hline \multirow[t]{4}{*}{0} & Laboratory & $1.6 \mathrm{~B} \mathrm{a}$ & $1.0 \mathrm{Ba}$ & 10.0 A a & $5.2 \mathrm{~B} \mathrm{a}$ & $6.3 \mathrm{Aa}$ & $1.4 \mathrm{~B} \mathrm{a}$ & 0.02 \\
\hline & Citrus & $2.2 \mathrm{Ca}$ & $0.6 \mathrm{Ca}$ & $11.5 \mathrm{~A}$ a & $6.2 \mathrm{~B} \mathrm{a}$ & $6.8 \mathrm{Ba}$ & $1.5 \mathrm{Ca}$ & 0.03 \\
\hline & Sugarcane & $3.0 \mathrm{Ca}$ & $1.8 \mathrm{Ca}$ & $12.5 \mathrm{~A}$ a & $5.8 \mathrm{~B} \mathrm{a}$ & $5.8 \mathrm{Ba}$ & $1.5 \mathrm{Ca}$ & 0.02 \\
\hline & Pvalue & 0.45 & 0.56 & 0.78 & $0.54^{\mathrm{S}}$ & 0.78 & 0.65 & \\
\hline \multirow[t]{4}{*}{5} & Laboratory & $44.1 \mathrm{~B} \mathrm{~b}$ & $1.5 \mathrm{Da}$ & 33.7 B b & $10.3 C \mathrm{C}$ & 43. $5 \mathrm{~A} a$ & $1.5 \mathrm{Da}$ & 0.03 \\
\hline & Citrus & $40.2 \mathrm{~B} a$ & $1.0 \mathrm{Da}$ & $54.7 \mathrm{~A}$ a & $16.6 \mathrm{Cb}$ & 42. $4 \mathrm{~B} \mathrm{a}$ & $1.5 \mathrm{Da}$ & 0.02 \\
\hline & Sugarcane & $50.7 \mathrm{~B}$ a & $3.8 \mathrm{D} \mathrm{a}$ & $55.3 \mathrm{~A} a$ & $24.3 C a$ & $42.8 \mathrm{~B} \mathrm{a}$ & $1.7 \mathrm{Da}$ & 0.02 \\
\hline & $P$ value & 0.02 & 0.32 & 0.03 & 0.03 & 0.65 & 0.56 & \\
\hline \multirow[t]{4}{*}{10} & Laboratory & $42.5 B C$ & $1.9 \mathrm{Da}$ & $46.5 \mathrm{~A} b$ & $14.8 C C$ & $44.3 \mathrm{~B} \mathrm{a}$ & $1.3 \mathrm{D} \mathrm{a}$ & 0.01 \\
\hline & Citrus & $51.9 \mathrm{~A} \mathrm{~b}$ & 4.4 D a & $54.8 \mathrm{~A} a$ & $29.9 \mathrm{Cb}$ & $45.5 \mathrm{~B} \mathrm{a}$ & 1.4 D a & 0.02 \\
\hline & Sugarcane & $57.2 \mathrm{~A}$ a & 4.6 D a & $61.4 \mathrm{~A}$ a & $32.7 \mathrm{Ca}$ & $47.9 \mathrm{~B} \mathrm{a}$ & 1.6 D a & 0.01 \\
\hline & $P$ value & 0.03 & 0.45 & 0.02 & 0.02 & 0.76 & 0.68 & \\
\hline \multirow[t]{4}{*}{20} & Laboratory & $41.9 A C$ & $2.2 \mathrm{Ca}$ & $47.0 \mathrm{~A} a$ & $16.9 \mathrm{~B} \mathrm{C}$ & 48.4 $\mathrm{A} a$ & $2.3 \mathrm{Ca}$ & 0.01 \\
\hline & Citrus & $54.4 \mathrm{Ab}$ & $4.5 \mathrm{Ca}$ & $59.1 \mathrm{~A}$ a & $34.9 \mathrm{~B} \mathrm{~b}$ & $50.3 \mathrm{~A} a$ & $3.1 \mathrm{Ca}$ & 0.02 \\
\hline & Sugarcane & $57.7 \mathrm{~A} a$ & $5.1 \mathrm{Ca}$ & $60.8 \mathrm{~A} a$ & 38.8 B a & $50.6 \mathrm{~A}$ a & $3.5 \mathrm{Ca}$ & 0.02 \\
\hline & $P$ value & 0.02 & 0.43 & 0.03 & 0.02 & 0.34 & 0.23 & \\
\hline \multirow[t]{4}{*}{30} & Laboratory & $50.7 \mathrm{~A} b$ & $3.2 \mathrm{Ca}$ & $54.4 \mathrm{~A} a$ & 15.7 B b & $49.5 \mathrm{~A} a$ & $1.6 \mathrm{Ca}$ & 0.01 \\
\hline & Citrus & $74.7 \mathrm{~A} a$ & $4.8 \mathrm{Ca}$ & $57.3 \mathrm{~B} \mathrm{a}$ & $34.7 \mathrm{Ca}$ & $53.2 \mathrm{~B} \mathrm{a}$ & $1.8 \mathrm{Ca}$ & 0.03 \\
\hline & Sugarcane & $72.0 \mathrm{Aa}$ & $4.3 \mathrm{Ca}$ & $58.9 \mathrm{~B} \mathrm{a}$ & $38.5 \mathrm{Ca}$ & $52.5 \mathrm{~B} \mathrm{a}$ & $1.8 \mathrm{Ca}$ & 0.02 \\
\hline & $P$ value & 0.01 & 0.56 & 0.32 & 0.02 & & 0.21 & \\
\hline
\end{tabular}

Note. ${ }^{1}$ Averages followed by same letter do not differ by Scott-Knott at $5 \%$ probability, lowercase letter, compared with the corresponding column for each condition, and capital letter, compared in the line corresponding type of formulations (diluted or undiluted) of pesticides, do not differ by Scott-Knott at 5\% probability. Bold percentages penetrations above 5\% - failed by ISO 27065.

be related to its high viscosity, which prevents its passage between the pore spaces of the seams. However, under the same conditions, the diluted Roundup Original SL formulation showed the highest penetration values ( $>70 \%)$.

The penetration of a pesticide through a seam is due to the presence of needle puncture holes, and depends on the physical-chemical characteristics of the formulation or the active ingredient. This was studied by Dimit et al. ${ }^{[24]}$ using two pesticides (dicofol $(42 \%$ a.i.) and etridiazole ( $25 \%$ a.i.)), with the emulsifiable concentrateds being diluted with water to $12 \%$ solutions. The two pesticides were applied to different types of material, including denim, and the greatest penetration was shown by the etridiazole formulation. ${ }^{[24]}$

Classification. The penetration values for the seams were higher than of the material without use or washing, failing to meet the ISO 27065 for the diluted and concentrated formulations of Nufos EC and the diluted Supera $\mathrm{SC}$ formulation. According to the ISO testing of the efficiency of material and seams, this should not be marketed for use with these pesticides. The seams of the garment without use and washing were classified according to ISO 27065 because the penetration is less than $5 \%$ for the concentrated formulations of Roundup Original SL and Supera SC following 30 uses and washings. This also occurred for the classification of the material of the garment, i.e., this formulation of these pesticides can make contact with the clothing and not contaminate the worker.
Correlation between penetration of the material and seams of the garment. There was a significant positive correlation between the number of washings and penetration of the diluted and concentrated formulations of Roundup Original SL, Nufos EC, and Supera SC into the material of the protective garment (Table 4). In other words, a greater number of uses and/or washings were associated with increased penetration of these formulations into the material and seams of the protective clothing. Repellency was negatively correlated with the number of uses and/or washings. The different formulations showed different degrees of penetration of the pesticides into the material and seam, according to the number of uses and washings (as well as the ISO classification). There

Table 4. Pearson's correlation coefficient among the percentage of penetration in the material and seams of garment and the parameters for the pesticide spray washes, body parts garment and use conditions.

\begin{tabular}{lrr}
\hline & \multicolumn{2}{c}{ Penetration } \\
\cline { 2 - 3 } Variables & Material & Seam \\
\hline Washing & $\mathbf{0 . 3 9}$ & $\mathbf{0 . 2 7}$ \\
$\mathrm{pH}$ & 0.05 & 0.00 \\
Superficial tension & $\mathbf{0 . 4 4}$ & $\mathbf{0 . 5 2}$ \\
Viscosity & $\mathbf{0 . 2 6}$ & $\mathbf{0 . 4 7}$ \\
Conductivity & $\mathbf{0 . 4 1}$ & $\mathbf{0 . 4 0}$ \\
Formulations & $\mathbf{0 . 2 7}$ & -0.02 \\
Concentrations & $\mathbf{0 . 2 8}$ & $\mathbf{0 . 7 0}$ \\
Conditions & $\mathbf{0 . 3 1}$ & 0.01 \\
Body & $\mathbf{0 . 3 2}$ & 0.01 \\
\hline
\end{tabular}

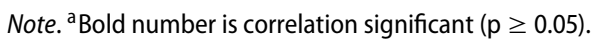




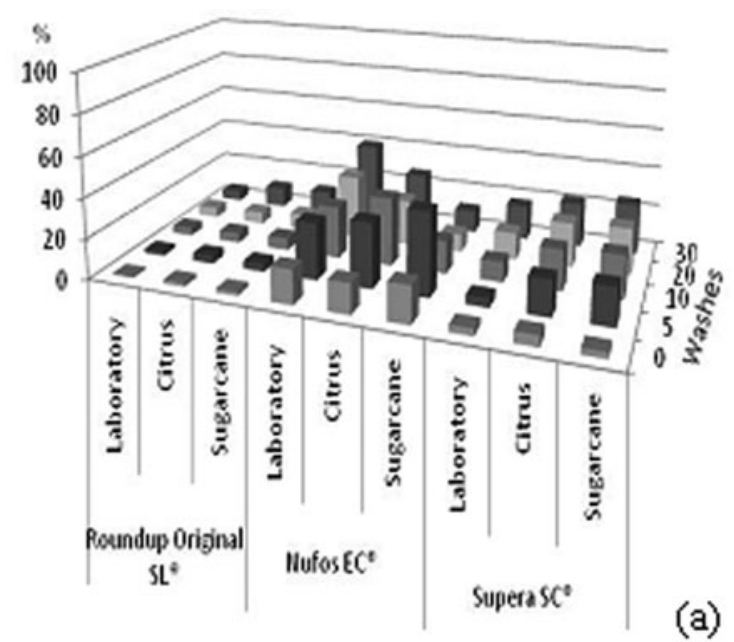

(a)

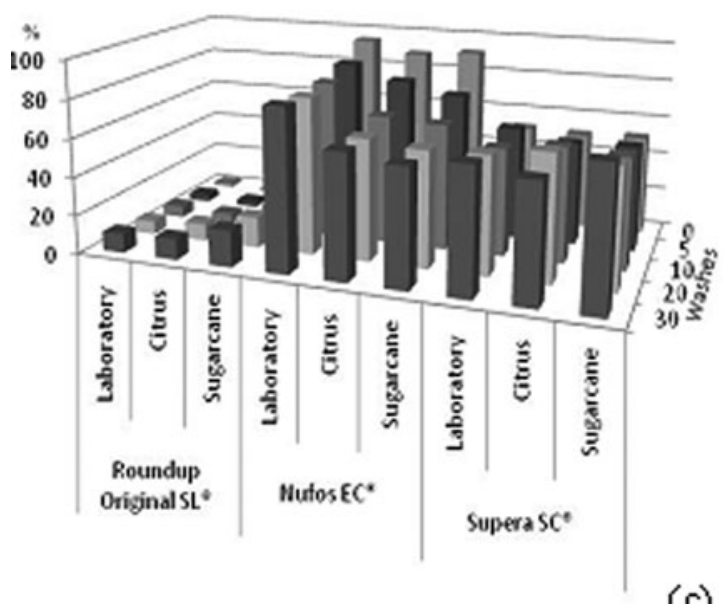

(c)

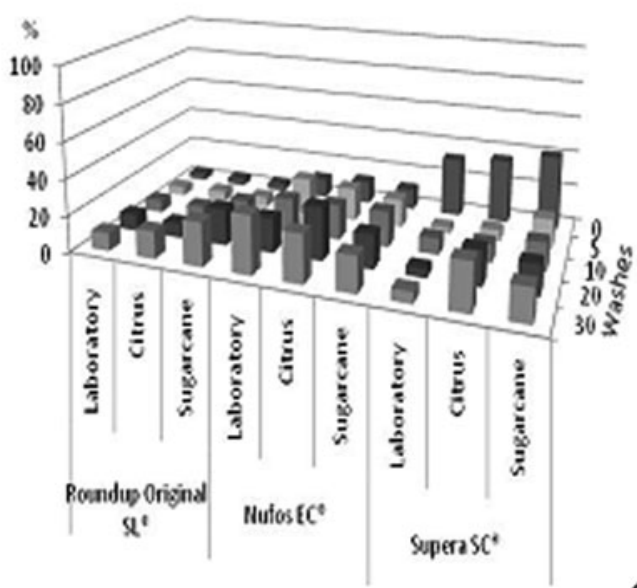

(b)

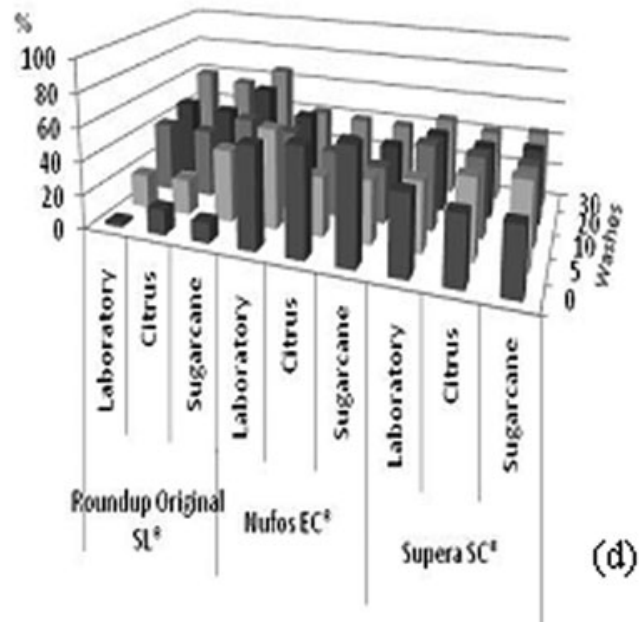

Figure 4. Percentage of retention of formulations Roundup Original SL, Nufos EC, Supera SC, in the material (a), and seam (c). Percentage of retention of diluted formulations Roundup Original SL, Nufos EC, Supera SC in the material (b), and seam (d), to each situation of use and washes.

was a significant correlation between penetration and formulation type (Table 4). Tests of the efficiency of protective materials must consider the type of formulation to be used. The $\mathrm{pH}$ of a pesticide formulation has no significant relationship to its penetration into the material and seams of protective garments. The characteristics (surface tension, viscosity, conductivity) of the diluted and concentrated formulations were negatively correlated with penetration into the material and seams (in other words, the higher the values of these variables, the lower the penetration). A negative correlation of superficial tension with the penetration of pesticides was also reported by Lee and Obendorf. ${ }^{[21]}$ The conductivity of the pesticide formulations is associated with ionic charge (positive or negative) present in surfactants they contain, and this charge's interaction with cotton fabric can increase liquid penetration into fabric. Cotton fabrics are negatively charged due to their carboxyl groups. ${ }^{[25]}$ The type of formulation can influence the penetration of pesticides. The presence of the adjuvants in the formulation, especially the organic solvents which may decrease the interfacial tension and increase the drop cloth spread ability and wettability. ${ }^{[26]}$ The formulation concentration (diluted or concentrated) was negatively associated with the penetration of the pesticides through the seam and was strongly negatively associated with penetration through the material (indicating that the clothing provided better protection of the worker against the undiluted formulations). The greater penetration of the diluted formulations through the material and seam could be explained by their lower viscosities.

The conditions in which the clothing and formulations were used (in the field or in the laboratory) had a significant effect on the degree of penetration of the material. The data (Table 2) showed that the lowest pesticide penetrations were obtained for the material that was washed in 

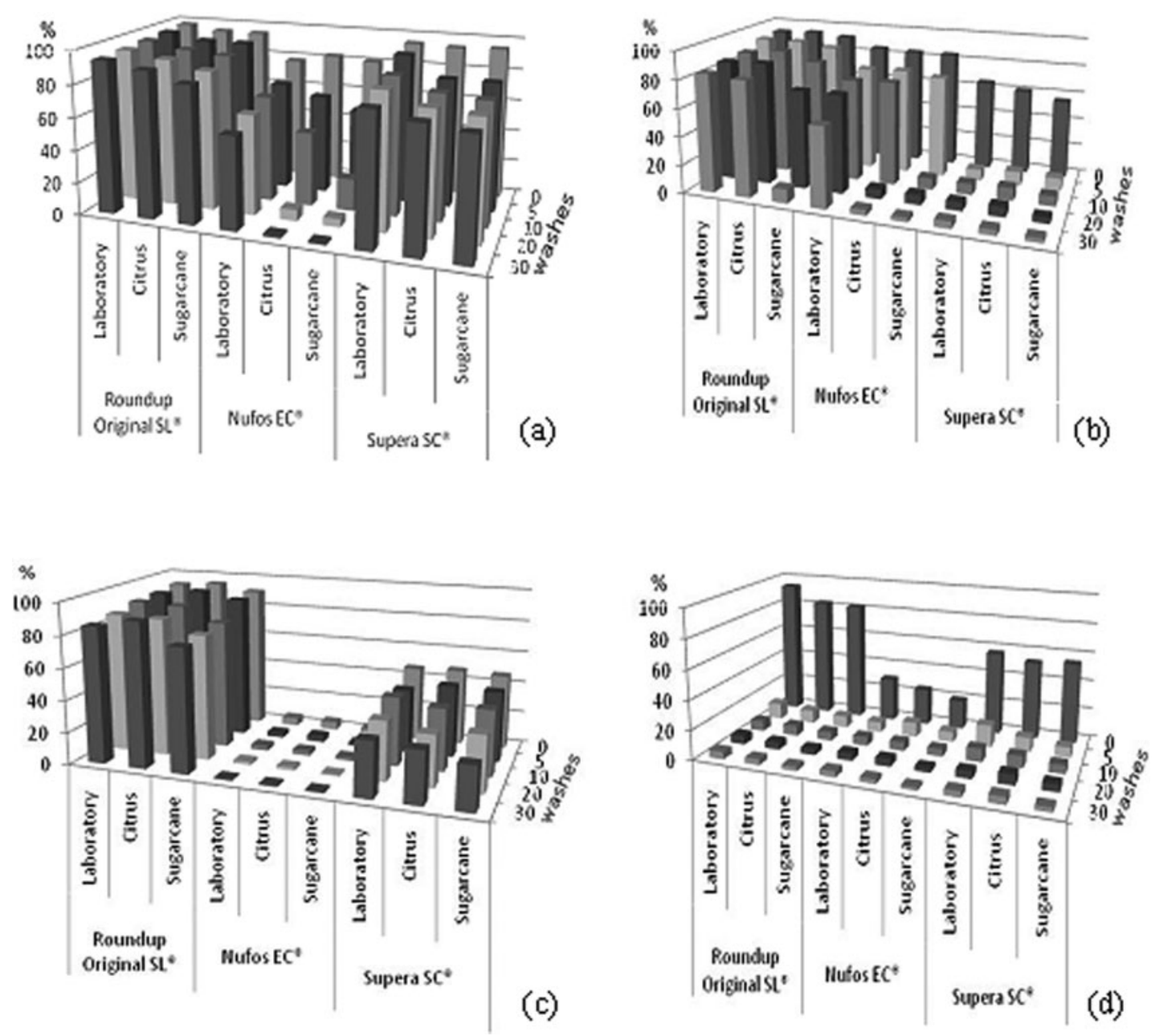

Figure 5. Percentage of repellency of formulations Roundup Original SL, Nufos EC, Supera SC, in the material (a), and seams (c). Percentage of repellency of diluted formulations Roundup Original SL, Nufos EC, Supera SC in the material (b), and seams (d) to each situation of use and washes.

the laboratory; use of the protective clothing in the field, followed by washings, resulted in greater opening of the pores of the material.

The analysis of the seam and material from different parts of the body has been associated with the penetration due to the abrasion and use in the field, mainly by using the clothing in cane sugar fields, in which the variation between the body parts have been around $25-34 \%$. The greater range of dermal exposure of herbicide applicators in the field for different body parts, resulting in higher CV\%, was caused by the inner dosimeter. ${ }^{[27]}$

\section{Retention in the material and seam}

The percentage retention of pesticide formulations in the garment varied of according to the degree of dilution of the formulation, the conditions of use and washing of the garments and the presence of seams (Figure 4). There was greater retention of the diluted formulations, compared to the concentrated products, which could be explained by the lower viscosity following dilution and consequently increased uptake by the fibers of the fabric. This would likely be the case for clothing in real situations where the pesticides are used.

The percentage retention values were higher for the seam than for the material, for both the concentrated formulations (Figures $4 \mathrm{a}$ and $4 \mathrm{c}$ ) and the diluted formulations (Figures $4 \mathrm{~b}$ and $4 \mathrm{~d}$ ).

Among the concentrated formulations, the Nufos EC pesticide showed greatest retention in the material after 30 washes in the laboratory, and $95 \%$ retention in the seam of the clothing prior to any washing, with values decreasing during the course of the washings (Figure 4a). The fact that the highest retention values were obtained for undiluted Nufos EC was not related to viscosity; a possible explanation could have been the acidic $\mathrm{pH}$ of the formulation, which was likely to have caused degradation of the fabric.

The retention of the concentrated Nufos formulation in the seams increased from $83-94.75 \%$ for clothes washed in the laboratory while when the clothes were 
used in sugarcane plantations, there was a drastic increase from $60.5-91.2 \%$.

The greatest retention of diluted pesticide in the seam of the garment was found for Roundup Original SL, with an increase from $12 \%$ to $67 \%$. In contrast, the retention of Nufos EC in the seams of clothing used in the sugarcane plantations decreased from $67 \%$ to $39 \%$. In these cases, the penetration was influenced by the interactions of the different pesticide molecules with the fabric fibers.

Shaw and Abbi related retention of diluted atrazine $(0.23 \%$ active ingredient $)$ of $11.6 \%$, in fabric of cotton/polyester for pippet method with cotton fabric (277 $\mathrm{g} / \mathrm{m}^{2}$ ) with fluorochemichal finish. ${ }^{[4]}$

\section{Repellency in the material and seams}

The percentage repellence obtained with the different pesticide formulations varied according to dilution, conditions of use of the garments, and the presence of seams (Figure 5). The percentage repellence values obtained using the concentrated formulations (Figures $5 \mathrm{a}$ and $5 \mathrm{c}$ ) were higher for the material than for the seam, with the exception of Roundup Original SL, for which the values were similar. In the case of the diluted Supera SC formulation, the percentage repellence values were similar for the material and the seam. However, for the other dilute formulations, the repellency of the material was higher than that of the seam (Figures $5 \mathrm{~b}$ and $5 \mathrm{~d}$ ).

Water-oil repellent material finished with polyurethane and Sontara tested after wash showed effect sharply decreased in first cleaning, due to removal of lamella in water-oil repellent finished clothing material, as well as increasing the number of pores of finished after wash, causing reduction of oil-repellency. ${ }^{[28]}$ Greater repellency of the material, relative to the seams of the garment, was obtained for the concentrated formulations than for the diluted formulations. This could be attributed to the needle holes, which increased the porosity of the seam, relative to the material. Decreased viscosity of the diluted formulations also led to reduced repellency during the course of the uses and washings. Various types of fabrics with different constitutions, such as polyester, cotton, and polyamide, were washed several times according to the ISO 6330 standard, resulting in alteration of characteristics such as weight, thickness, and the warp/wale direction of the fibers of the fabric. ${ }^{[7]}$ These alterations explained the changes in the repellency of the material and seam of the clothing under the different conditions of use and washing. The repellency of material and seams for pesticides was above $80 \%$ for Roundup Original SL, exception for the clothes used in sugarcane after 10 washes when contamined with diluted formulation, and to other pesticides and other use situation, there was decrease in repellency below $10 \%$. The ISO
16602 requires that the repellency of the materials and seams of protective sets chemicals are classified into three classes: Class 1: repellency> 80\%; Class 2: Repellency> 90\%; Class 3: Repellency $>95 \%$. Thus, the percentage repellence lower than $80 \%$ are failed. ${ }^{[29]}$

\section{Conclusions}

The presence of seams in protective clothing reduced its efficiency in the control of dermal exposure, except when protecting against the undiluted formulation of Supera SC. The dilution of formulations increases penetration into the material and seams of clothing.

The highest penetration of contaminated seams was by Nufos EC (diluted and undiluted), followed by the diluted formulations of Supera SC and Roundup Original SL ${ }^{\circ}$. The highest penetration of the protective material was into that used in the field and contaminated with Supera SC diluted formulation followed by Nufos EC ${ }^{\oplus}$ diluted formulation and Nufos EC undiluted formulation.

The effects of usage plus washing of protective clothing increased the penetration of pesticides into the material and seams in relation to clothing that was only washed in the laboratory. This affects the classification proposed by ISO 27065, i.e., efficiency tests of protective clothing conducted before it is marketed should consider the use factor.

The strongest correlations between physicochemical parameters of diluted or undiluted formulations of pesticides and penetration into the material were those of tension and conductivity; for seams, they were the concentration, tension, and viscosity of the pesticide. Efficiency tests of protective clothing are needed to determine what types of formulations can be used to protect the worker. This research studied diluted formulations with $5 \%$ active ingredient according to the proposal of ISO 27065 , it would be necessary to study real dilutions that are applied in the field.

\section{Acknowledgment}

The authors thank the Cosan/Bonfim Unit for conducting the field research.

\section{Funding}

São Paulo Research Foundation (process number 2005/60387).

\section{References}

[1] Obendorf, S.K., E. Csiszár, D. Maneefuangfoo and J. Borsa: Kinetic transport of pesticide from contaminated 
fabric through a model skin. Arch. Environ. Contam. Toxicol. 45:283-288 (2003).

[2] Aprea, C., L. Centi, S. Santini, L. Lunghini, B. Banchi, and G. Sciarra: Exposure to omethoate during stapling of ornamental plants in intensive cultivation tunnels: influence of environmental conditions on absorption of the pesticide. Arch. Environ. Contam. Toxicol. 49:577-588 (2005).

[3] Shaw, A. and R. Abbi: Compararison of gravimetric and gas chromatographic methods for assessing perfomance of textile materials against liquid pesticide penetration. Int. J. Occup. Saf. Ergon. 10:255-261 (2004).

[4] Shaw, A., E. Cohen, T. Hinz, and B. Herzig: Laboratory test methods to measure repellency, retention and penetration of liquid pesticides through protective clothing. Part I: comparison of three test methods. Textile Res. J. 71:879-884 (2001).

[5] Protano, C., M. Guidotti, and M. Vitali: Perfomance of diffeent work clothing types for reducing skin exposure to pesticide during open field treatment. Bull. Environ. Contam. Toxicol. 83:115-119 (2009).

[6] Yoon, B., and S. Lee: Designing waterproof breathable materials based on electro and assessing the performance characteristic. Fibers Poly. 12:57-62. (2011).

[7] Gore, S.E., R.M. Laing, D.J.C. Wilson, and B.E. Niven: Fabrics standardizing a pre-treatment cleaning procedure and effects of application on apparel. Text Res. J. 76:455464 (2006).

[8] International Organization for Standardization (ISO): ISO 27065:2011. Protective Clothing-Performance Requirements for Protective Clothing Worn by Operators Applying Pesticides. Geneva: Technical Committee ISO/TC 94.

[9] International Organization for Standardization (ISO): ISO 22608:2004. Protective Clothing - Protection against Liquid Chemicals - Measurement of Repellency, Retention, and Penetration of Liquid Pesticide Formulations through Protective Clothing Materials. Geneva, Switzerland.

[10] American Society for Testing and Materials (ASTM): ASTM D3825 - 09:2009. Standard Test Method for Dynamic Surface Tension by the Fast-Bubble Technique. International West Conshohocken, PA: ASTM.

[11] American Society for Testing and Materials (ASTM): ASTM D 2196-10:2010. Standard Test Methods for Rheological Properties of Non-Newtonian Materials by Rotational (Brookfield type) Viscometer. ASTM International. West Conshocken, PA: ATSM.

[12] American Society for Testing and Materials (ASTM): ASTM D1777-96:2011. Standard Test Method for Thickness of Textile Materials. West Conshohocken, PA: ASTM, International.

[13] International Organization for Standardization (ISO): SO 6330:2000. Textiles - Domestic Washing and Drying Procedures for Textile Testing. Geneva, 2000.

[14] Scott, A.J., and M.A.A. Knott: Cluster analysis method for grouping means in the analysis of variance. Biometrics 30:507-512 (1974).

[15] Ferreira, D.F.: Análises estatísticas por meio do Sisvar para Windows 4.0. In: Reunião anual brasileira da sociedade internacional de biometria (ed Universidade Federal de São Carlos) São Carlos, Brazil, July, 2000, pp. 255-258.

[16] Csiszar, E., J. Borsa, I. Rácz, and S.K. Obendorf: Reduction in human exposure to pesticide using traditional work clothing fabrics with chemical finishing: carboxymethylation and starch. Arch. Environ. Contam. Toxicol. 3:129-134 (1998).

[17] Faulde, M.K., W.M. Uedelhoven, and R.G. Robbins: Contact toxicity and residual activity of different permethrin-based fabric impregnation methods for Aedes aegypti (diptera: culicidae), Ixodes ricinus (acari: ixodidae), and Lepisma saccharina (thysanura: Lepismatidae). J. Med. Entomol. 40:935-941 (2003).

[18] Leonas, K.K., and J.O. De Jonge: Effect of Functional Finish Barriers on Pesticide Penetration. In Performance of Protective Clothing: Second Symposium. STP \# 900, R.L. Barker and G.C. Coletta (eds.) West Conshohocken, PA: ASTM. pp. 177-186 (1986).

[19] Kwon, Y., and A. Sarmadi: Wettability of nonwoven fabrics: effect of laundering on water absorption. Cloth Textiles Res. J. 13:17-29 (1995).

[20] Obendorf, S.K., R. Mejldal, A. Varanasi, and M. Thellersen: Kinetic study of lipid distribution after washing with lipases: microscopy analysis. J. Surfact. Deterg. 4:43-55 (2001).

[21] Lee, S., and S.K. Obendorf: Statistical model of pesticide penetration through woven work clothing fabrics. Arch. Environ. Contam. Toxicol. 49:266-273 (2005).

[22] Hubal, E.A., M.G. Nishioka, W.A. Ivancic, M. Morara, and P. P. Egechy: Comparing surface residue transfer efficiencies to hands using polar and no polar fluorescent tracers. Environ. Sci. Tech. 42:934-949 (2008).

[23] Rodrigues, B.N., and F.S. Almeida: Guia de Herbicida. 5th ed. London, 2005.

[24] Dimit, C.A., E.P. Easter, and J.O. De Jonge: The effect of seams and closures on pesticide penetration through fabrics. In Performance of Protective Clothing, 4th ed., J.P. McBriarty and N.V. Henry (eds). Philadelphia: ASTM 1133, 1992. pp. 418-426.

[25] Sher, H.B.: Advances in pesticide formulation technology. In Advances in Pesticide Formulation Technology, H.B. Sher (ed.). Washington, DC: American Chemical Society, 1984. pp. 1-7.

[26] Stana-kleischek, K., S. Strnad, and V. Ribitsch: Surface characterization and adsorption abilities of cellulose fibers. Polym. Eng. Sci. 36:1412-1419 (1999).

[27] Espanhol-Soares, M., L.A.S. Nociti, and J.G. MachadoNeto: Procedures to evaluate the efficiency of protective clothing worn by operators applying pesticide. Ann. Occup. Hyg. 57:1041-1053 (2013).

[28] Saleh, M.A., A. Kamel, el-Demerdash, J. Jones: Penetration of household insecticides through different types of textile fabrics. Chemosphere 36:1543-1552 (1998).

[29] International Organization for Standardization (ISO): ISO 16602: Protective Clothing for Protection against Chemicals - Classification, Labelling and Performance Requirements. Geneva, 2007. 